\title{
Revista CEPAL cumple 40 años
}

El número inaugural de Revista CEPAL fue publicado en el primer semestre de 1976. Han transcurrido 40 años desde que esa primera edición, bajo la dirección de su fundador, Raúl Prebisch, irrumpiera en el debate académico sobre el desarrollo de América Latina y el Caribe, con enfoques novedosos y heterodoxos acerca de los aspectos y políticas de la problemática regional. Han sido cuatro décadas de fructífera labor con el propósito de reflejar, del modo más cercano posible a la realidad histórica de cada etapa en el proceso de desarrollo, las complejidades estructurales, las coyunturas específicas y el surgimiento de nuevos fenómenos nacionales, regionales y globales involucrados en ese proceso.

Durante estos 40 años Revista CEPAL ha publicado más de un millar de artículos, abriendo sus páginas a las contribuciones de los más destacados economistas, sociólogos, politólogos y académicos de América Latina y otras latitudes, vinculados con las más importantes instituciones especializadas en los aspectos económicos, societales y medioambientales del desarrollo.

Revista CEPAL ha generado una colección de 118 números regulares y sus correspondientes versiones homólogas en inglés (CEPAL Review). A este acervo se suman cinco ediciones extraordinarias, destacándose el número especial de 1998 en conmemoración de los 50 años de la CEPAL, dos números en francés (2005 y 2010), uno en portugués (2010) y uno en chino mandarín (2012).

Nuestra publicación se ha constituido en un instrumento de gran relevancia para difundir las más importantes ideas-fuerza generadas en el debate académico como contribución al desarrollo regional. Así ha sido desde sus primeros artículos enfocados en la naturaleza del capitalismo periférico y de los estilos de desarrollo en los años setenta —elaborados por Prebisch y Aníbal Pinto (su segundo director), respectivamente-, pasando por el análisis crítico de los efectos de dichos estilos en el medioambiente, la crisis de la deuda y la década pérdida en los años ochenta, la difusión de ideas referidas a la transformación productiva con equidad y las reformulaciones neoestructuralistas a partir de los años noventa, que en el decenio actual han sido continuadas bajo el enfoque de la igualdad y el desarrollo inclusivo.

Revista CEPAL, desde su edición número 95 de agosto de 2008, está indizada en el Social Sciences Citation Index (SSCI), publicado por Thomson Reuters, objetivo que se destaca como uno de los grandes hitos durante el período de Oscar Altimir como director de la revista. Este logro ha enriquecido su acervo de autores, su línea editorial y su factor de impacto, constituyéndose en una de las revistas con mayor número de citas en el contexto de las publicaciones académicas producidas en la región. Durante los últimos ocho años, la Revista fue dirigida por André Hofman, quien se acogió a retiro luego de casi 30 años de provechoso servicio en la CEPAL. Durante esta etapa de dirección, se instituyó por primera vez en la Revista un Consejo Editorial, compuesto por destacados especialistas en materias de desarrollo tanto de América Latina y el Caribe, como de otras regiones del mundo. Este período ha sido especialmente fecundo para nosotros, donde hemos dado cabida a nuevos temas, como las recientes crisis financieras internacionales, la desigualdad y sus múltiples aristas, el calentamiento global, la economía del cuidado y las problemáticas de la mujer en el proceso de desarrollo, entre muchos otros. Además, hemos ampliado nuestra cobertura geográfica al incluir nuevos análisis, especialmente en los casos del desenvolvimiento de las economías andinas y caribeñas.

Reflejo de este collage temático y geográfico es la presente edición especial de Revista CEPAL, alusiva a nuestro aniversario número cuarenta, en la que presentamos muchos de los temas antes mencionados. A través de esta edición aniversario, el actual equipo editorial de la Revista desea agradecer el apoyo permanente brindado a nuestra labor por Alicia Bárcena, Secretaria Ejecutiva de la CEPAL.Y asimismo, compartir con nuestros lectores esta rica experiencia editorial, renovando también el compromiso de plasmar nuevas contribuciones a los problemas del desarrollo en América Latina y el Caribe, con independencia académica y sujetos de manera irrestricta a nuestra línea de contenidos y estándares de calidad editorial.
Miguel TorRes

Editor Técnico

Revista CEPAL
Osvaldo Sunkel

Presidente Consejo Editorial

Revista CEPAL 